\title{
The anesthetic efficiency of retromolar infiltrations with two local anesthetic solutions of the same concentration in lower third molar surgery
}

\author{
Phouthala Sayphiboun', Kiatanant Boonsiriseth1, Basel Mahardawi1', Verasak Pairuchvej', Bishwa Prakash Bhattarai', \\ Natthamet Wongsirichat ${ }^{1}$ \\ 1Department of Oral \& Maxillofacial Surgery, Faculty of Dentistry, Mahidol University, Bangkok, Thailand \\ ${ }^{2}$ Walailak University International College of Dentistry, Bangkok, Thailand
}

Background: Mandibular third molar removal is the most common surgical procedure encountered in oral and maxillofacial clinics. It also presents the greatest challenges and controversies for surgeons when surgical removal is considered. Furthermore, diverse anesthesia results and success rates are achieved after using the same concentrations of different solutions or the same amounts of local anesthetics. The purpose of this study was to examine the efficiency of using double-cartridge $(3.4 \mathrm{ml}$ ) 4\% lidocaine (high concentration) and 4\% articaine with a 1:100000 epinephrine infiltration in the retromolar region for impacted lower third molar surgery. Methods: This double-blind study included 30 patients with symmetrically impacted lower third molars. The patients were randomly selected to receive $4 \%$ articaine on one side and $4 \%$ lidocaine on the other, as a local anesthetic for third molar surgery. The onset, duration of soft-tissue numbness, pulpal sensitivity, amount of additional local anesthetic needed, pain score during the surgical procedure, and duration of the operation were recorded.

Results: The results of this research indicate that $86.7 \%$ of the operations in the $4 \%$ articaine group and $83.3 \%$ of those in the $4 \%$ lidocaine group were successful. Furthermore, the outcomes in both groups were not statistically significant $(\mathrm{P}>0.05)$. Numbness onset occurred faster in the articaine group than it did in the lidocaine group. However, the duration of soft-tissue anesthesia and pain scores recorded immediately postoperatively were similar. Conclusion: It is concluded that $4 \%$ lidocaine and $4 \%$ articaine had a similar infiltration efficacy in the retromolar region and both local anesthetics are adequate for impacted lower third molar surgery. There were no statistically significant differences between the two local anesthetics regarding pain control and the duration of soft-tissue numbness during the procedure.

Keywords: Articaine; Concentration; Double Cartridges; Infiltration; Lidocaine; Third Molar Surgery.

This is an Open Access article distributed under the terms of the Creative Commons Attribution Non-Commercial License (http://creativecommons.org/licenses/by-nc/4.0/) which permits unrestricted non-commercial use, distribution, and reproduction in any medium, provided the original work is properly cited.

\section{INTRODUCTION}

The most common surgical procedure found in oral surgery clinics is mandibular third molar surgery (MTMS). It presents a challenge for surgeons when indications for removal are considered [1]. For removals, local anesthesia has to be provided for pain relief in dental

Received: April 8, 2020 • Revised: May 16, 2020 • Accepted: June 8, 2020

Corresponding Author: Natthamet Wongsirichat, Oral Maxillofacial Surgery Department, Faculty of Dentistry, Mahidol University, 6 Yothi Street, Rachathewee District, 10400 Bangkok, Thailand

Tel: +6602200777(ext. 3333) E-mail: natthamet.won@mahidol.ac.th

Consultant in the International College of Dentistry Committee, Walailuk University International College of Dentistry 979/42-46 Phahonyothin Road 19th floor SM Tower Phayathai District, 10400 Bangkok, Thailand

Tel: +6622990935 Mobile: +66819095625 E-mail: natthamet.wo@mail.wu.ac.th

Copyright@ 2020 Journal of Dental Anesthesia and Pain Medicine 
surgery [2]. Inferior alveolar nerve block is the conventional procedure for MTMS $[3,4]$. This technique has a high success rate; however, injection procedures lead to complications in many instances. This was reported by several authors who mentioned the occurrence of pain, nerve injury, trismus, needle breakage, and hematoma, as well as aphonia of the chin happening during the inferior alveolar nerve block technique, indicating that it may not be possible to entirely exclude the chance of damage [5].

The infiltration technique is a viable option for achieving inferior alveolar nerve block for the removal of lower posterior teeth, with similar outcomes. El-Kholey et al. [6] used the buccal infiltration technique by injecting the area of the wisdom tooth instead of using the inferior alveolar nerve block technique. In a prospective clinical study, Poorni et al. compared the inferior alveolar nerve block and infiltration techniques using $4 \%$ articaine in patients with irreversible pulpitis. The results showed that the effects of the infiltration technique are similar to those of the inferior alveolar nerve injection, for the lower posterior teeth [7]. Moreover, Silva-Junior, Almeida, and Groppo reported on using the infiltration technique after inferior alveolar nerve injections to release intraoperative pain. They concluded that buccal infiltration after inferior alveolar injections enhances the effectiveness of inferior alveolar nerve injections that show a $10-26.3 \%$ failure rate [8]. During endodontic treatment in the mandibular posterior area, supplemental infiltration for pulpal numbness can be achieved when the inferior alveolar nerve injection does not succeed, with a $58 \%$ success rate in patients with irreversible pulpitis [9].

Furthermore, different solutions and concentrations of local anesthetic agents provide different results, as shown in a study by Jain et al. in which 70 patients were evaluated using $4 \%$ articaine and $2 \%$ lidocaine to assess intraoperative pain and the onset and period of tissue anesthesia during impacted mandibular third molar removal. The results indicated that, when compared with $2 \%$ lidocaine, $4 \%$ articaine had a faster onset and longer period of tissue numbness [10]. In a study by Martin et al., the efficacies of $1.8 \mathrm{ml}$ and $3.6 \mathrm{ml}$ of $4 \%$ articaine were compared. Eighty-six adult volunteers were given two $1.8 \mathrm{ml}$ and $3.6 \mathrm{ml}$ injections of $4 \%$ articaine as buccal infiltrations of asymptomatic mandibular first molars for electrical pulp testing. The authors concluded that the 3.6 $\mathrm{ml}$ group had a higher efficacy than the $1.8 \mathrm{ml}$ group, with $70 \%$ and $50 \%$ success rates, respectively [11].

In 2016, a study that included 30 patients was carried out by Sawang et al. during which $1.7 \mathrm{ml}$ and $3.4 \mathrm{ml}$ of $4 \%$ articaine infiltrations were performed at retromolar sites for MTMS. Their results showed an 83.3\% success rate in the $3.4 \mathrm{ml}$ group, which had a longer soft-tissue anesthesia interval and less intraoperative pain, and a $53.3 \%$ success rate in the $1.7 \mathrm{ml}$ group. In the conclusion of this study, the researchers suggested that infiltration using $3.4 \mathrm{ml}$ of $4 \%$ articaine in the retromolar region can be an effective alternative practice for MTMS [12].

In a randomized clinical trial study by Shruthi et al., the authors used $2 \%$ lidocaine and $4 \%$ articaine on 25 cases to evaluate the anesthetic efficiency of both solutions for MTMS. Their result showed that 4\% articaine had a faster onset (the mean onset times were 2.07 minutes for $4 \%$ articaine and 2.18 minutes for $2 \%$ lidocaine) and a longer anesthesia duration (4.28 hours for $4 \%$ articaine and 3.52 hours for $2 \%$ articaine); however, based on the visual analog scale (VAS) pain score, both solutions had similar efficacies [13].

Ping et al. studied hemodynamic change by comparing $2 \%$ lidocaine with $4 \%$ lidocaine in impacted lower third molar surgery, conducting a split-mouth single-blinded study with 31 volunteers. The outcomes showed that using $2 \%$ lidocaine caused higher arterial blood pressure and a higher heart rate; however, 4\% lidocaine can improve the efficacy and achievement of inferior alveolar nerve block. Therefore, they suggested that $4 \%$ lidocaine can be a more viable local anesthetic solution than $2 \%$ lidocaine, for MTMS [14].

As observed by us after reviewing the literature, there is still no study that compares the efficacy of double cartridges $(3.4 \mathrm{ml})$ of the same concentration of $4 \%$ 
Table 1. The eligibility criteria for patient selection in this research study

\begin{tabular}{|c|c|}
\hline Inclusion criteria & Exclusion criteria \\
\hline $\begin{array}{l}\text { 1. Age between } 18 \text { and } 45 \text { years. } \\
\text { 2. No smoking or alcohol abuse. } \\
\text { 3. Symmetrically impacted lower third molars on both sides. } \\
\text { 4. Patients who have at least one non-decayed asymptomatic lower first } \\
\text { or second molar on both sides. } \\
\text { 5. Patients who understand and can follow directions given by an operator. }\end{array}$ & $\begin{array}{l}\text { 1. Systemic disease including hypertension, hypotension, cardiovascular } \\
\text { problems, or serious medical conditions. } \\
\text { 2. Allergy to local anesthesia. } \\
\text { 3. Pregnancy or currently lactating. } \\
\text { 4. Inflammation in the area of the lower third molar or site of injection. } \\
\text { 5. Lack of competence to follow instructions and participate in the study. }\end{array}$ \\
\hline
\end{tabular}

lidocaine $\mathrm{HCl}$ with $4 \%$ articaine $\mathrm{HCl}$ during infiltration in the retromolar region for MTMS. Thus, this study was conducted for that purpose, as well as to generally evaluate the anesthetic efficacy during infiltration of $4 \%$ lidocaine (high concentration) and 4\% articaine in the retromolar region for MTMS.

\section{METHODS}

\section{Materials}

This double-blinded clinical randomized split-mouth controlled trial included 11 males $(36.66 \%)$ and 19 females $(63.34 \%)$, with an age range between 18 and 37 years (mean age 22 years). The patients had bilaterally symmetrical lower third molars as examined on dental panoramic radiographs. The sample size calculation was performed using the G Power 3.1.0 software, assuming an $\alpha$ error of 0.05 and a power of $95 \%$.

\section{Eligibility criteria for patient selection}

The inclusion and exclusion criteria are shown in Table 1. A total of 30 patients underwent 60 operations. Thirty of the operations, which comprised the articaine group, were carried out, using the infiltration technique, with 3.4 $\mathrm{ml}$ of $4 \%$ articaine $\mathrm{HCl}$ with 1:100,000 epinephrine. The other 30 operations, which comprised the lidocaine group, were performed using the same technique but with 3.4 $\mathrm{ml}$ of $4 \%$ lidocaine $\mathrm{HCl}$ with 1:100,000 epinephrine.

All operations were performed by two surgeons: one of them injected the local anesthetic and the other was the operator. If one side was injected with double cartridges $(3.4 \mathrm{ml})$ of $4 \%$ lidocaine $\mathrm{HCl}$, the other side received double cartridges $(3.4 \mathrm{ml})$ of $4 \%$ articaine $\mathrm{HCl}$, using the same infiltration technique on both sides. The patients were not informed about which type of local anesthetic agent was used in each appointment. A three-week washout period was carried out for each volunteer prior to making the appointment for surgery on the other side.

\section{Methods of surgical procedure}

\subsection{Administration of local anesthetic}

\section{A. Pre-injection assessment}

Before the injection, a pinprick test and an Electrical Pulp Test (EPT) were performed on the canine and the lower first molar on the same side as that of the lower third molar that was intended to be removed. If the patient's canine or lower first molar were missing or non-vital, the first premolar and/or lower second molar was tested instead. The EPT test was carried out to provide the baseline measurements for comparison with the post-injection values.

\section{B. Injection assessment}

The infiltration technique was performed in the retromolar area of the mandible. Following the drying of the alveolar mucosa with a sterile $2 " \mathrm{x} 2$ " gauze, $0.2 \mathrm{ml}$ of a topical anesthetic agent covering the tip of a cotton-tip applicator was placed for one minute at the injection point. The needle was smoothly placed into the retromolar area (needle insertion) until the needle was situated at the retromolar pad of the lower third molar (needle placement). Along with the needle placement, no anesthetic solution was deposited in that area. After reaching the target site, the full volume of articaine $\mathrm{HCl}$ or lidocaine $\mathrm{HCl}$ was deposited at a rate of $1 \mathrm{ml}$ per minute without injection at the lingual site. 


\section{Post-injection assessment}

a) Pain scale during local anesthetic administration

The investigator administered the local anesthetic using double cartridges $(3.4 \mathrm{ml})$ of $4 \%$ articaine and $4 \%$ lidocaine, and each patient was required to rate the level of pain that they felt for the period of local anesthetic administration and immediately postoperatively on the 0 to $100 \mathrm{~mm}$ line of the VAS.

b) Subjective onset of the local anesthetic

The patients were asked if they felt numbness at the lower lip and tongue every minute for five minutes to evaluate the onset of the local anesthetic after the injection. When the patient started to feel numbness at the area of the lower lip and tongue on the same site as that of the injection, the operator recorded this as the onset of local anesthesia.

c) Post-injection EPT assessment

The EPT device was used from the baseline to 10 minutes after the local anesthetic injection. For the post-injection evaluation, the pulp was tested at the same site as that of the third molar on the canine or premolar side that has been tested at the baseline using the electrical pulp testing device (SybronEndo ${ }^{\circledR}, 2006$ model, USA). The operator recorded all the EPT values.

\section{Pain assessment}

The perception of pain differs for each patient. Each patient's pain experience during the surgical procedure was identified using the VAS and the Numerical Rating Scale (NRS) [15]. In this research, the VAS was followed to measure pain while the injection was being administered and immediately postoperatively, and the NRS was used to measure pain intraoperatively.

The VAS contains a 100-mm-long line for assessing pain, starting from the left side and following the following divisions: no pain $(0-4 \mathrm{~mm})$, mild pain (5-44 $\mathrm{mm}$ ), moderate pain (45-74 $\mathrm{mm})$, and unbearable pain (75-100 mm). The operator explained the VAS principle to every patient so that they may be familiar with it and choose correctly. Therefore, the patients were able to describe and score their pain accurately.

During the surgical procedure, the operator asked the patients to score and evaluate their pain at each step of the surgery. The patients received the necessary information regarding the NRS in terms of pain intensity level ranging from 1 to 10 , i.e. no pain (0), mild pain (1-3), moderate pain (4-6), and severe pain (7-10). This was done before the initiation of the surgical procedure to help the patient score his or her pain reliably.

Postoperatively, the level of pain felt by the patients was recorded by crossing it on the VAS.

\section{E. Surgical assessment}

The position of the third molar was assessed following the Pell and Gregory classification [16]. Tooth exposure was reached after raising a mucoperiosteal flap. A straight surgical handpiece with a carbide round bur was used to remove the bone covering the molar tooth, along with copious irrigation with normal saline. Later, a carbide fissure bur was used to separate the tooth into parts considering its type of impaction, to be able to remove it in smaller pieces. The surgical site was irrigated copiously toward the end of the procedure and the flap was closed with 3.0 silk sutures. The overall duration of the surgery was recorded, starting from the first incision and ending with the last suture.

During the operation, if it was necessary, additional local anesthetic was administered by intraligamentous infiltration or intrapulpal $0.85 \mathrm{ml}$ injection, and the total volume and technique of administering additional anesthesia were recorded.

\section{F. Postoperative assessment}

Verbal and written postoperative care instructions were given to the patients and medications were prescribed to them. The patients were observed at the clinic for an hour after surgery to manage any sudden drug side effects or complications. The patients completed a case record regarding the resolution of lower lip numbness or any complications that happened at home. The patients returned for follow-up on the seventh day after the operation.

\section{Ethical support of the clinical study}

This study was permitted and approved by the Ethical 
Table 2. Success rates of local anesthetics

\begin{tabular}{|c|c|c|c|}
\hline & \multicolumn{2}{|c|}{ Mean \pm SD } & \multirow{2}{*}{$P$ value } \\
\hline & $4 \%$ articaine & $4 \%$ lidocaine & \\
\hline Success rate, $\mathrm{n}(\%)$ & $26(86.7 \%)$ & $25(83.3 \%)$ & 1.000 \\
\hline Total volume of anesthetic (ml) & $3.54 \pm 0.39$ & $3.59 \pm 0.48$ & 0.645 \\
\hline
\end{tabular}

Committee of Research in Human Beings, the Institutional Review Board of Mahidol University, Faculty of Dentistry/Faculty of Pharmacy, with certificate number COA.No.MU-DT/PY-IRB 2019/DT016.

\section{Statistical analysis}

The immediate postoperative pain, objective onset, pulpal response at the baseline and 10 minutes later, operation length and period of soft-tissue anesthesia were evaluated using the paired t-test or Wilcoxon signed-rank test.

McNemar's test was carried out to determine the distribution of all cases according to the success and failure of the analysis of the two groups. The general linear model was used to calculate the distribution of the intraoperative pain scores (NRS) at every step of the surgical procedure.

\section{RESULTS}

The purpose of this research was to study the efficiency of $4 \%$ lidocaine and $4 \%$ articaine infiltrations at the retromolar area for the removal of the impacted mandibular third molar. This study recruited 30 patients. The sample comprised of $11(36.66 \%)$ males and 19 females $(63.34 \%)$, with the age of the patients ranging from 18 to 37 years (mean age 21.9 years). The volunteers were two-fold intervened for impacted lower third molar surgery. A total of 60 operations were carried out. In 30 operations, infiltration with $3.4 \mathrm{ml}$ of $4 \%$ articaine $\mathrm{HCl}$ with 1:100,000 epinephrine was used, and, in the other 30 , with $3.4 \mathrm{ml}$ of $4 \%$ lidocaine $\mathrm{HCl}$ with $1: 100,000$ epinephrine. No adverse events were observed during any of the visits and no complications were recorded.

\section{Success rate of local anesthesia}

The success criterion in this study was defined as no additional local anesthetic during the operation. The results of this study showed success rates of $86.7 \%$ in the $4 \%$ articaine group and $83.3 \%$ in the $4 \%$ lidocaine group. There was no statistically significant difference between the two groups $(\mathrm{P}$ value $=1.000)$, as shown in Table 2.

\section{Onset, duration of local anesthesia and surgical time}

The onset of the local anesthesia was evaluated depending on whether any sensitivity of the tongue and lower lip on the same side as that of the surgical procedure was recorded. From our results, we found that the $4 \%$ articaine group (1.94 \pm 0.79 minutes) had a faster onset than the $4 \%$ lidocaine group ( $2.53 \pm 0.88$ minutes). This was statistically significant, with a $\mathrm{P}$ value of 0.018 .

The duration of the local anesthesia in this study indicated that no statistically significant differences were observed between the $4 \%$ articaine group $(237.91 \pm 83.91$ minutes) and 4\% lidocaine group $(246.56 \pm 65.03$ minutes), with a $\mathrm{P}$ value of 0.610 . The surgical time in the $4 \%$ articaine group was $24.06 \pm 7.28$ minutes, which was similar to that in the $4 \%$ lidocaine group, namely $24.43 \pm 8.50$ minutes. No significant differences regarding surgical time were observed between the two groups either, as shown in Table 3.

\section{Pulpal anesthesia}

In this study, an EPS device was used in both groups, to confirm the pulpal anesthesia, at the baseline and 10 minutes post local anesthetic injection. Therefore, the status of 60 healthy canine and 60 healthy molar teeth was tested. Pulpal anesthesia distribution was tested by 
Table 3. Onset, duration of local anesthesia, and surgical time

\begin{tabular}{lcc}
\hline & \multicolumn{2}{c}{ Type of local anesthesia } \\
\cline { 2 - 3 } & $4 \%$ articaine & $4 \%$ lidocaine \\
\hline Onset (minutes) & $1.94 \pm 0.79$ & $2.53 \pm 0.88$ \\
Duration of local anesthesia (minutes) & $237.91 \pm 83.91$ & $246.56 \pm 65.03$ \\
Surgical time & $24.06 \pm 7.28$ & $24.43 \pm 8.50$ \\
\hline
\end{tabular}

Table 4. Distribution of cases according to the incidence of pulpal sensibility

\begin{tabular}{|c|c|c|c|c|}
\hline & & \multicolumn{2}{|c|}{ Mean \pm SD } & \multirow{2}{*}{$P$ value } \\
\hline & & $4 \%$ articaine & $4 \%$ lidocaine & \\
\hline \multirow[t]{2}{*}{ Canine } & Baseline & $22.83 \pm 12.44$ & $23.37 \pm 11.19$ & 0.835 \\
\hline & $10 \mathrm{~min}$ & $57.60 \pm 13.55$ & $56.50 \pm 13.03$ & 0.746 \\
\hline \multirow[t]{2}{*}{ Molar } & Baseline & $23.97 \pm 10.87$ & $25.90 \pm 12.43$ & 0.337 \\
\hline & $10 \mathrm{~min}$ & $55.53 \pm 16.18$ & $57.73 \pm 12.59$ & 0.533 \\
\hline
\end{tabular}

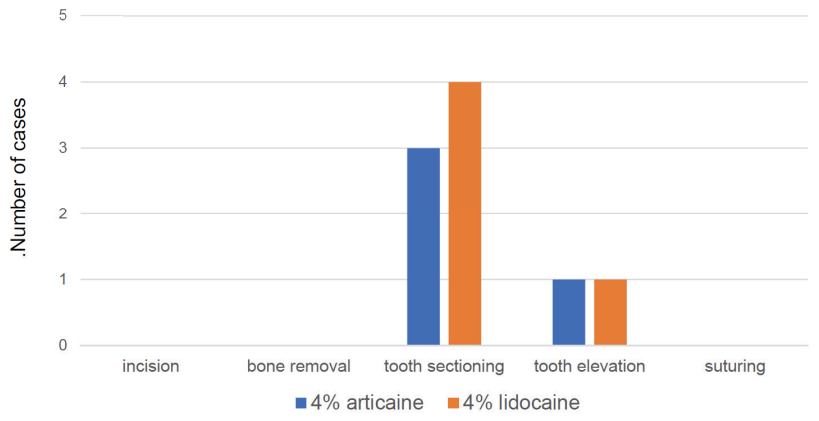

Fig. 1. This figure shows the number of cases that needed additional anesthesia intra-operatively. The $x$-axis demonstrates the steps of the surgical procedure, and the $y$-axis is the number of cases. There were four cases in $4 \%$ articaine group, three of them during the tooth sectioning step, and one during the tooth elevation step. On the other hand, there were five cases in $4 \%$ lidocaine group, four of them during tooth sectioning, and one during tooth elevation.

analyzing pulpal sensibility at the baseline and 10 minutes after the injection with the local anesthetic. No differences between the two groups were found. This is detailed in Table 4.

\section{Case distribution according to the type of anesthetic and additional anesthesia}

Fig. 1 shows the number of cases that needed additional anesthesia intraoperatively. The $4 \%$ lidocaine group required more additional anesthesia than the $4 \%$ articaine group. Four cases in the $4 \%$ articaine group and five in the $4 \%$ lidocaine group required additional anesthesia intraoperatively. Those cases required additional anesthesia during the tooth-sectioning period. No additional

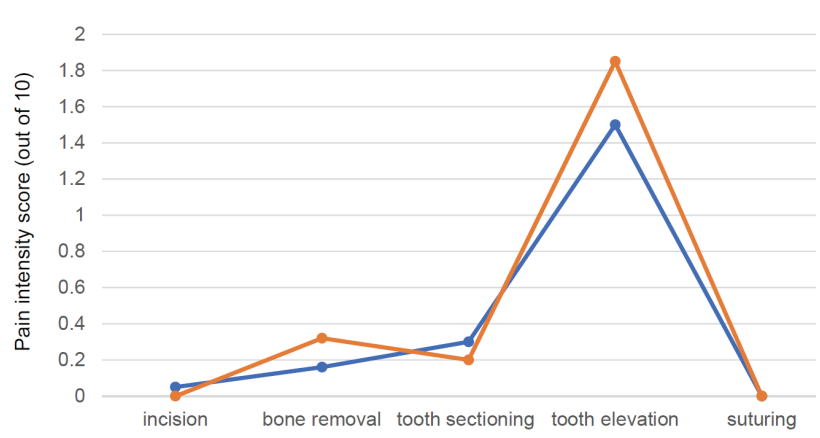

$\rightarrow 4 \%$ articaine $\rightarrow 4 \%$ lidocaine

Fig. 2. This figure demonstrates the comparison of intra-operation pain intensity of 30 cases between $4 \%$ articaine and $4 \%$ lidocaine group. The $x$-axis represents the steps of the surgical procedure, and the $y$-axis represents the pain intensity score. The highest score on the scale is 10. None of the patients reported a score more than 2, as shown from this figure.

local anesthesia was required during incision, bone removal, or the closing sutures.

\section{Pain intensity}

Fig. 2 shows a comparison, for 30 cases, between the intraoperative pain intensity in the $4 \%$ articaine group and that in the $4 \%$ lidocaine group. The pain scores were similar in both groups. They were high during the tooth elevation period and then decreased during the suture placement period. There was no significant difference between the two groups ( $\mathrm{P}$ value 0.764).

Table 5 shows pain intensity while injecting the local anesthesia and immediately postoperatively. The pain scores were slightly higher in the $4 \%$ lidocaine group 
Table 5. VAS scores of volunteers during injection and postoperative pain

\begin{tabular}{lccc}
\hline & $4 \%$ articaine & $4 \%$ lidocaine & $P$ value \\
\hline Injection & $20.13 \pm 9.12$ & $22.80 \pm 9.87$ & 0.087 \\
Post-op* & $20.46 \pm 1.92$ & $22.76 \pm 2.38$ & 0.748 \\
\hline
\end{tabular}

*Post-op, postoperation

$(22.80 \pm 9.87)$ than they were in the $4 \%$ articaine group $(20.13 \pm 9.12)$ during the injection of the local anesthetic. However, the results in the two groups were not significantly different ( $\mathrm{P}$ value 0.087 ). Similarly, no statistically significant differences in postoperative pain scores were observed $(20.46 \pm 1.92$ and $22.76 \pm 2.38$, respectively), with a $\mathrm{P}$ value of 0.748 .

\section{DISCUSSION}

This study was designed to compare double-cartridges (3.4 $\mathrm{ml}$ ) of $4 \%$ articaine $\mathrm{HCl}$ and $4 \%$ lidocaine $\mathrm{HCl}$ used during infiltration into the retromolar site for MTMS. The results demonstrated that no difference in efficiency exists between the two solutions for MTMS. In addition, no clinical adverse effects were recorded during the study period. In this study, the total volumes of local anesthesia in the two groups, $3.54 \pm 0.39 \mathrm{ml}$ in the articaine group and $3.59 \pm 0.48 \mathrm{ml}$ in the lidocaine group, were not significantly different.

Regarding the success rate, onset and duration, need of additional anesthetic, profoundness of pulpal anesthesia, and total volume of local anesthetic, the results showed no statistically significant differences between the $4 \%$ lidocaine and $4 \%$ articaine group.

In a review of local anesthetics, it was stated that articaine seems to have a higher activity than lidocaine [17], which agrees with the results of this study, as the $4 \%$ articaine solution had a higher success rate than the $4 \%$ lidocaine solution. However, no statistically significant difference between the two local anesthetics was found, with a $\mathrm{P}$ value of 1.000 .

Moreover, statistically significant differences in the onset of local anesthetics were observed between the two groups, with a $\mathrm{P}$ value of 0.018 . In other words, $4 \%$ articaine (1.94 minutes) had a faster onset than 4\% lidocaine (2.53 minutes). This outcome was similar to that in a previous study, which used the conventional injection technique for MTMS [14]. On the other hand, Meechan et al. showed that $2 \%$ lidocaine infiltration at the buccal area of the mandibular first molar had a faster onset than that recorded in this study [18].

The duration of the anesthesia in the lidocaine group was not significantly longer than that in the articaine group: 246.56 minutes and 237.91 minutes, respectively. In a previous study, the lidocaine double-cartridge group showed soft-tissue anesthesia that was longer than that in this study (292.92 minutes) [12].

Pulpal anesthesia was examined by an EPT device at the baseline and 10 minutes after the injection with the total volume of the local anesthetic on a healthy canine and molar. The results showed no statistically significant difference between the two groups. When comparing the EPT values at baseline and 10 minutes after the injection, the EPT values increased for both the canine and the molar. On the other hand, a previous study showed a significant difference between $4 \%$ lidocaine and $4 \%$ articaine after pulpal testing on the mandibular first molar [19].

An acidic $\mathrm{pH}$ of local anesthetic solutions, as stated in the literature, is more likely to lead to a burning sensation on the tissue while the drug is being administered [20,21]. In this study, we used $4 \%$ articaine and $4 \%$ lidocaine. Moreover, the VAS scores showed an unexpected occurrence of pain, with scores of $20.13 \pm$ 9.12 in the $4 \%$ articaine group and $22.80 \pm 9.87$ in the $4 \%$ lidocaine group, during the injection of the local anesthetic. There were no statistically significant differences in postoperative pain between the two groups (20.46 \pm 1.92 in the $4 \%$ articaine group and $22.80 \pm 9.87$ 
in the $4 \%$ lidocaine group). This was similar to the results of a previous study, which showed that the VAS scores in two groups of $4 \%$ articaine and $2 \%$ lidocaine were not significantly different [12]. We found no significant differences during drug administration and the postoperative period in the two groups.

To obtain the intraoperative NRS score, the patients were asked to rate their pain on a scale from 0 to 10 . No significant differences between the two local anesthetic solutions were found. The highest pain score was recorded during the tooth elevation period. The reason for this might be the higher pressure applied by the operator during tooth elevation.

There were no reports regarding immediate postoperative paresthesia or any adverse complications, during the operation, immediately postoperatively, or on the seventh day of follow up. As mentioned before, articaine and lidocaine have similarly low toxicities [17]. Lidocaine toxicity can result when an overdose is administered or delivered via an intravascular route or even if it is given by the correct route but is excessive [22]. However, in this study, the safety dose was used for the surgery and all of the cases were healthy patients, thus attempting to eliminate the chance of any adverse effects or complications.

Based on the results of this study, it might be concluded that $4 \%$ lidocaine with 1:100,000 epinephrine has, when used in the infiltration technique at the retromolar area, effects similar to those of $4 \%$ articaine with $1: 100,000$ epinephrine, for MTMS. This can be concluded considering the same success rate, period of soft-tissue anesthesia, level of intraoperative pain, and amount of supplemental anesthesia for the two solutions.

Hence, an additional conclusion to be mentioned here is that, when compared to lidocaine, articaine has a relatively faster anesthesia onset when used in the infiltration technique in the retromolar region. Furthermore, the authors would like to state that a high volume and concentration of $4 \%$ lidocaine in the infiltration technique might not lead to any adverse reactions in healthy patients as long as it is used according to recommendations.

Nevertheless, clinicians should keep in mind that the infiltration technique may not always be sufficient for lower third molar surgery or the posterior mandibular teeth in general, especially as it has been proven to not be as successful as the traditional inferior alveolar nerve block [23]; however, the infiltration technique is still relatively successful and can be a good option, in certain cases where postoperative bleeding may cause problems to certain patients, such as those under coagulation medications or with certain coagulation disorders, or even in certain situations where some patients feel extremely anxious and uncomfortable with the standard inferior alveolar never block. In those instances, it would be advantageous to use the infiltration technique to reduce discomfort in anxious patients or control bleeding in patients with any postoperative bleeding risk. Therefore, the authors recommend to clinicians to view the infiltration technique as a viable option to be used when cases necessitate it and to consider the results from this study, as well as those from other studies, when selecting anesthetic agents.

\section{AUTHOR ORCIDS}

Phouthala Sayphiboun: https://orcid.org/0000-0002-6445-6387

Kiatanant Boonsiriseth: https://orcid.org/0000-0002-4492-3080

Basel Mahardawi: https://orcid.org/0000-0001-5113-535X

Verasak Pairuchvej: https://orcid.org/0000-0002-9566-2407

Bishwa Prakash Bhattarai: https://orcid.org/0000-0003-3359-9032

Natthamet Wongsirichat: https://orcid.org/0000-0003-3005-2680

\section{AUHOR GONIRHBUIIONS}

Phouthala Sayphiboun: Data curation, Formal analysis, Investigation, Methodology, Resources, Writing - original draft

Kiatanant Boonsiriseth: Project administration, Resources, Supervision

Basel Mahardawi: Resources, Validation, Visualization, Writing review \& editing

Verasak Pairuchvej: Supervision, Visualization

Bishwa Prakash Bhattarai: Data curation, Visualization, Writing review \& editing

Natthamet Wongsirichat: Conceptualization, Project administration, Supervision, Writing - review \& editing 
ACKNOWLEDGMENTS: The authors would like to thank the staff, colleagues, and dental assistants, including the co-workers from the Department of Oral and Maxillofacial Surgery, Faculty of Dentistry, Mahidol University. The authors also thank the IDCMR association. This research was financially supported by a research grant from the IDCMR. Finally, the authors would like to thank Christian Estacio for editing and revising the language of this manuscript.

DECLARATION OF PATIENT CONSENT: The authors certify that they have obtained all appropriate patient consent forms. In the forms, the patient (s) has/have given his/her/their consent for his/her/their images and other clinical information to be reported in this journal. The patients understand that their names and initials will not be published and due efforts will be made to conceal their identity but that anonymity cannot be guaranteed. DECLARATIONS OF INTERESTS: The authors declared conflicts of interest.

FUNDING AND SPONSORSHIP: This research study received funding from the IDCMR association. This research was financially supported by a research grant from the IDCMR.

ETHICS APPROVAL FOR THE CLINICAL STUDY: This study was approved by the Faculty of Dentistry/Faculty of Pharmacy, Mahidol University, the Institutional Review Board (MU-DT/PY-IRB), with study approval number “COA.No.MU-DT/PY-IRB 2019/DT016”.

CLINICAL TRIAL REGISTRATION: There is no requirement for this in our faculty because clinical research is controlled by the Ethical Committee of Research in Human Beings of the Dentistry and Pharmacy Mahidol University Institutional Review Board.

\section{REFERENCES}

1. Shepherd JP, Brickley M.Surgical removal of third molars. BMJ 1994; 309: 620-1.

2. Porto GG, Vasconcelos BCDE, Gomes ACA, Albert D.
Evaluation of lidocaine and mepivacaine for inferior third molar surgery. Med Oral Patol Oral Cir Bucal 2007; 12: E60-4.

3. AlHindi M, Rashed B, AlOtaibi N. Failure rate of inferior alveolar nerve block among dental students and interns. Saudi Med J 2016; 37: 84-9.

4. Kim C, Hwang KG, Park CJ. Local anesthesia for mandibular third molar extraction. J Dent Anesth Pain Med 2018; 18: 287-94.

5. Pogrel MA, Schmidt BL, Sambajon V, Jordan RC. Lingual nerve damage due to inferior alveolar nerve blocks: a possible explanation. J Am Dent Assoc 2003; 134: 195-9.

6. El-Kholey KE. Anesthetic Efficacy of 4\% articaine during extraction of the mandibular posterior teeth by using inferior alveolar nerve block and buccal infiltration techniques. J Maxillofac Oral Surg 2017; 16: 90-5.

7. Poorni S, Veniashok B, Senthilkumar AD, Indira R, Ramachandran S. Anesthetic efficacy of four percent articaine for pulpal anesthesia by using inferior alveolar nerve block and buccal infiltration techniques in patients with irreversible pulpitis: a prospective randomized doubleblind clinical trial. J Endod 2011; 37: 1603-7.

8. da Silva-Junior GP, de Almeida Souza LM, Groppo FC. Comparison of articaine and lidocaine for buccal infiltration after inferior alveolar nerve block for intraoperative pain control during impacted mandibular third molar surgery. Anesth Prog 2017; 64: 80-4.

9. Matthews R, Drum M, Reader A, Nusstein J, Beck M. Articaine for supplemental buccal mandibular infiltration anesthesia in patients with irreversible pulpitis when the inferior alveolar nerve block fails. J Endod 2009; 35: 343-6.

10. Jain NK, John RR. Anesthetic efficacy of 4\% articaine versus $2 \%$ lignocaine during the surgical removal of the third molar: a comparative prospective study. Anesth Essays Res 2016; 10: 356-61.

11. Martin M, Nusstein J, Drum M, Reader A, Beck M. Anesthetic efficacy of $1.8 \mathrm{~mL}$ versus $3.6 \mathrm{~mL}$ of $4 \%$ articaine with 1:100,000 epinephrine as a primary buccal infiltration of the mandibular first molar. J Endod 2011; 37: 588-92.

12. Sawang K, Chaiyasamut T, Kiattavornchareon S, Pairuchvej V, Bhattarai BP, Wongsirichat N. Double versus 
single cartridge of $4 \%$ articaine infiltration into the retromolar area for lower third molar surgery. J Dent Anesth Pain Med 2017; 17: 121-7.

13. Shruthi R, Kedarnath N, Mamatha N, Rajaram $P$, BhadraShetty D, Articaine for surgical removal of impacted third molar; a comparison with lignocaine. J Int Oral Health 2013; 5: 48-53.

14. Ping B, Kiattavorncharoen S, Durward C, Im P, Saengsirinavin C, Wongsirichat N. Hemodynamic changes associated with a novel concentration of lidocaine $\mathrm{HCl}$ for impacted lower third molar surgery. J Dent Anesth Pain Med 2015; 15: 121-8.

15. Alghadir AH, Anwer S, Iqbal A, Iqbal ZA. Test-retest reliability, validity, and minimum detectable change of visual analog, numerical rating, and verbal rating scales for measurement of osteoarthritic knee pain. J Pain Res 2018; 11: 851-6.

16. Lima CJ, Silva LC, Melo MR, Santos JA, Santos TS. Evaluation of the agreement by examiners according to classifications of third molars. Med Oral Patol Oral Cir Bucal 2012; 17: e281-6.

17. Oertel R, Rahn R, Kirch W. Clinical pharmacokinetics of articaine. Clin Pharmacokinet 1997; 33: 417-25.
18. Meechan JG, Kanaa MD, Corbett IP, Steen IN, Whitworth JM. Pulpal anaesthesia for mandibular permanent first molar teeth: a double-blind randomized cross-over trial comparing buccal and buccal plus lingual infiltration injections in volunteers. Int Endod J 2006; 39: 764-9.

19. Nydegger B, Nusstein J, Reader A, Drum M, Beck M. Anesthetic comparisons of $4 \%$ concentrations of articaine, lidocaine, and prilocaine as primary buccal infiltrations of the mandibular first molar: a prospective randomized, double-blind study. J Endod 2014; 40: 1912-6.

20. Malamed SF. Handbook of local anesthesia. 5th ed. Philadelphia, Elsevier's Health Sciences. 2004.

21. Malamed SF, Gagnon S, Leblanc D. Articaine hydrochloride: a study of the safety of a new amide local anesthetic. J Am Dent Assoc 2001; 132: 177-85.

22. Weinberg L, Peake B, Tan C, Nikfarjam M. Pharmacokinetics and pharmacodynamics of lignocaine: A review. World J Anesthesiol 2015; 4: 17-29.

23. Awad S, Mourad SI. Extraction of mandibular posterior teeth: Comparison between standard inferior alveolar nerve block and local infiltration anesthesia. Egypt Dent J 2020; 66: 107-12. 